\title{
Measurement of Flux Linkage and Inductance Profile of SRM
}

\author{
Rakesh Saxena, Bhim Singh and Yogesh Pahariya
}

\begin{abstract}
The main goal in modeling of SRM is to provide a good accuracy over the entire speed and torque range. This paper introduces significant physical phenomenon that needs to be included in a realistic model of the SRM. The proposed methodology is applied on submersible pump switched reluctance motor for measurement of flux linkage and inductance of phase winding. Experimental results are well accurate for modeling and performance analysis of proposed SRM.
\end{abstract}

Index Terms- Flux Linkage, submersible pump, Simpson's rule, inductance profile.

\section{INTRODUCTION}

Growing interest of the switched reluctance motor drives has raised many analysis, design and measurement issues. One of the important aspects is the measurement of motor parameters to use in the analysis and design of the converter, prediction of the performance of drive etc. Recently the switched reluctance motor (SRM) is drawing considerable attention over $\mathrm{AC} \& \mathrm{DC}$ drives because it has several advantages over AC \&DC drives like simple and robust construction, no brushes, Low inertia and high torque to weight ratio, no rotor windings, simple power converter circuit etc.

The switched reluctance motor presently used in two main fields of application:

1) Variable speed - variable torque drive system where the medium and small size motors are used

2) Servo drives for position, speed or torque control where small size variable reluctance motors are used for incremental motion [9].

For proper design of converter system and performance analysis of the SRM, the knowledge of accurate flux linkage characteristics is necessary. The flux linkage and inductance profile of the srm is depend on the rotor position and phase current the family of the flux linkage characteristics (for different rotor positions) will have to be determined as accurately as possible in this paper we present the method for obtaining the flux linkage characteristics of SRM [1].

Rakesh Saxena is with the Electrical Engineering Department, at SGSITS, Indore (MP), India

Bhim Singh is with the Electrical Engineering Department at Indian Institute of Technolgy, Delhi (India)

Yogesh Pahariya is with the Electrical \& Electronics Engg. Department at Institute of Engg. \& Science, IPS Academy, Indore (MP), India

\section{II.PRINCIPLE OF OPERATION}

The cross section of 8/6 SRM is shown in Figure - 1, in which both the stator and the rotor are salient poles. The stator winding consists of a set of coils, each of which is wound on one pole. The reluctance of the flux path between the two diametrically opposite stator poles varies as a pair of rotor poles rotates in and out of alignment. Since inductance is inversely proportional to reluctance, the inductance of a phase winding is a maximum when the rotor is in the aligned position and a minimum when the rotor is in the non-aligned position. The rotor teeth tend to align with an energized phase in order to minimize the reluctance path. The aligned and unaligned positions are characterized by the properties summarized in Table - $\mathbf{1}$.

TABLE - 1 PROPERTIES OF THE ALIGNED AND UNALIGNED POSITIONS

\begin{tabular}{|l|l|}
\hline Aligned Position & Unaligned Position \\
\hline$\theta=0,180^{\circ}$ & $\theta= \pm 90^{\circ}$ \\
\hline Maximum inductance & Minimum inductance \\
\hline $\begin{array}{l}\text { Magnetic circuit liable } \\
\text { to saturate }\end{array}$ & $\begin{array}{l}\text { Magnetic circuit } \\
\text { unlikely to saturate }\end{array}$ \\
\hline $\begin{array}{l}\text { Zero torque and stable } \\
\text { equilibrium }\end{array}$ & $\begin{array}{l}\text { Zero torque and unstable } \\
\text { equilibrium }\end{array}$ \\
\hline
\end{tabular}

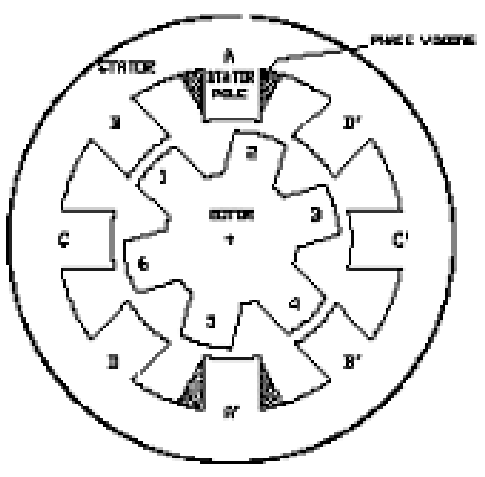

Figure - 1 8/6 Switched Reluctance Motor

With successively energizing of phases, the rotor can step around the in any direction as desired. The production of torque of the SRM depends upon the stator current magnitude regardless of the direction. A pulse of positive torque is produced if current flows in a phase winding as the inductance of that phase winding are increasing. A negative torque contribution is avoided if the current is reduced to zero 
before the inductance starts to decrease again. The rotor speed can be varied by changing the frequency of the phase current pulses while retaining synchronism with the rotor position [9].

In Figure 2(a), the machine is shown with phase-A aligned, i.e., at $0^{0}$. In Figure 2(b), the rotor position is at $15^{0}$ with respect to phase $\mathrm{B}$. Thus, with this machine configuration, phase B is midway to an aligned position. Figure 2(c) illustrates that the rotor position, with respect to phase $\mathrm{C}$, which is in quadrature with phase $\mathrm{A}$, is at $30^{\circ}$, thus, phase $\mathrm{C}$ is at an unaligned position [5].

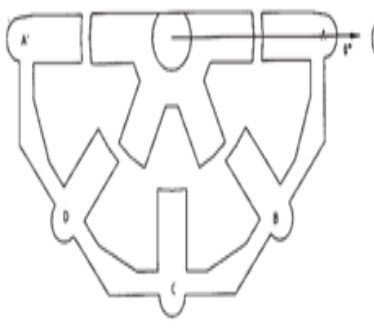

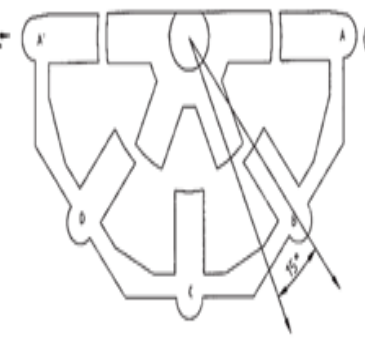

(b)

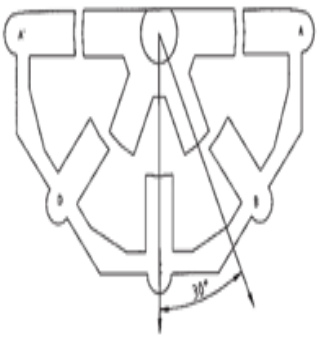

(c)

Figure - 2. (a) Phase A at aligned position. (b) Phases B and D at midway-to aligned position. (c) Phase $\mathrm{C}$ at unaligned position

\section{MATHEMATICAL SRM MODEL}

There are many approaches for modeling the SRM, such as lookup-table techniques, magnetic equivalent circuit analysis, cubic-spline interpolations and finite-element analysis (FEA). Magnetic equivalent-circuit analysis and FEA are computationally intense. The cubic-spline interpolations and lookup-table techniques require numerous flux-linkage current- position data, which are obtained either through experiments or using FEA, which are time-ineffective and tedious. SRM models obtained through analytic methods have been presented. Their principal advantage is that they allow for easier analysis of the machine, as they offer insight into its working, in formulating control strategies and in achieving high accuracy in performance computations because differentiation and integration are easier to perform [5].

The SRM drive system simulation is much more complex than ac \& dc motor drives because its operational region is mostly nonlinear [6]. The nonlinearity is introduced by the three factors:--

1) The nonlinear $\mathrm{B}-\mathrm{H}$ characteristics of the magnetic material.

2) The dependence of phase flux linkages on both the rotor position and current magnitude while in other machine it is dependent only on current magnitude.

3) The single source of excitation.

By using the proposed method a deviation of the current slope, which is not influenced by the motor speed can be derived. The deviation of the current slope is only related to input d.c. voltage and self inductance of motor. As a result the self inductance of the motor can be precisely estimate by detecting current slope. [8]

SRM models are generally made up of three parts: the electrical model, torque characteristics and mechanical model. The electrical circuit for one phase of SRM is shown in Figure 3.

Applying Kirchhoff voltage law thus voltage given by equation (1)

$$
v=i r+\frac{d \lambda(i, \theta)}{d t}
$$

Where $\mathrm{R}$ is phase resistance and $\lambda(i, \theta)$ is magnetic flux is given by equation (2)

$$
\lambda(i, \theta)=L(i, \theta) i
$$

Where $L(i, \theta)$ is the phase inductance, which varies as a function of rotor position (due to varying reluctance) and phase current (due to magnetic saturation).

Solve equation (1) to calculate magnetic flux at various rotor angles and current magnitudes from measures stator voltages, currents and resistance as given in equation (3)

$$
\lambda(i, \theta)=\int(v-i r) d t
$$

The electrical model of the SRM can be compared with d.c. motor by substituting (2) in (1) as follows

$$
\begin{gathered}
v=i r+\frac{d(L(i, \theta) i)}{d t} \\
=i r+L(i, \theta) \frac{d i}{d t}+i \frac{d(L(i, \theta))}{d t} \\
=i r+L(i, \theta) \frac{d i}{d t}+i \frac{d \theta}{d t} \frac{d(L(i, \theta))}{d \theta} \\
=i r+L(i, \theta) \frac{d i}{d t}+i \omega \frac{d(L(i, \theta))}{d \theta}
\end{gathered}
$$

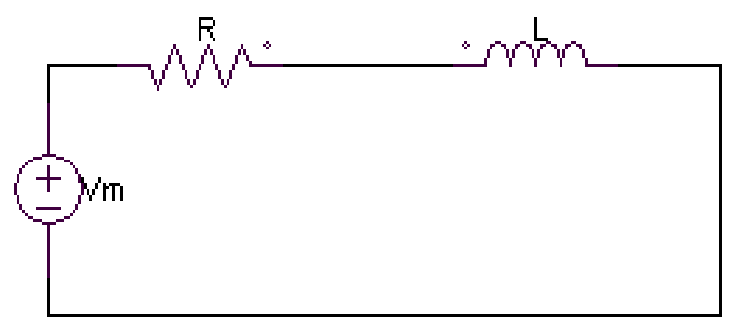

Figure 3 Electrical Model of One Phase of SRM

\section{CONVERTERS FOR SRM}

A number of power electronic converter circuits exist for 
Switched Reluctance Machines, which are generally allocable to most loads. The phase independence and unipolar current requirement have a wide variety of converters for SRM drives. For each stroke of the motor, the power electronic converter for a Switched Reluctance Motor is required to first provide a positive voltage loop to increase the flux in the phase winding. Second, it must have the ability to reduce the applied voltage if the desired current level is reached. Third, it must apply a negative voltage at turn off, also referred to as a negative voltage loop [9]. Some functional requirement of SRM converter should ideally meet:

1) It needs to control the voltage applied to the winding at low speed, so as to limit the winding current. Either voltage or current PWM control can be used.

2) It needs to have sufficiently high forcing voltage at each operation point so that the current is injected sufficient and quickly into the winding. This requirement is critical at high speed since the time available is decreased.

3 ) It has a high demagnetizing voltage in order to shorten the current tail, thus avoiding negative torque and / or permitting an extension of dwell angle.

4) It has to provide independent control of phase current in motors having current overlap, so that energy can be supplied to one phase while extracting it simultaneously from the other phase

5) It has to provide efficient energy recycling during a demagnetizing interval. This is an important requirement given the highly cyclical energy exchange between the converter and the motor.

6) It should isolate the ac network from the current pulse the shocks caused by the motor.

\section{V.METHADOLOGY}

V. METHADOLOGY.

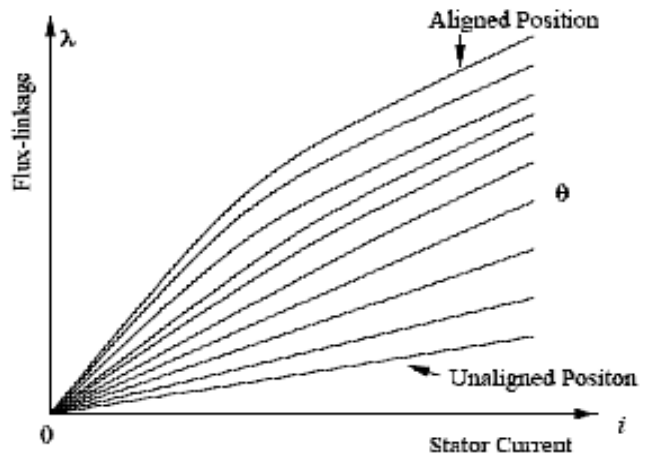

Figure 4 Ideal flux linkage characteristics of SRM

The flux linkage characteristics of SRM depend on the rotor position and the excited stator phase current. The ideal flux linkage characteristics of SRM are represented in Figure - 4. The flux linkage characteristics at aligned position are represented, when the stator interpolar axis is coincides with the rotor interpolar axis and the flux linkage characteristics at unaligned position are also represented. The flux linkage characteristics at the intermediate position shown, as the rotor position is changed from unaligned position to aligned position till the overlap of the pole approached [3].

The phase inductance of the SRM is depends on both the excitation current and rotor position. The measurement of inductance can be performed while the phase winding is excited with the appropriate d.c. current. The measurement of flux linkages can be implemented in two ways:--

7) By applying a constant voltage to phase winding and measuring the rising current.

8) First establishing a steady state d.c. current in the winding and then measuring the decaying current when the circuit is energized.

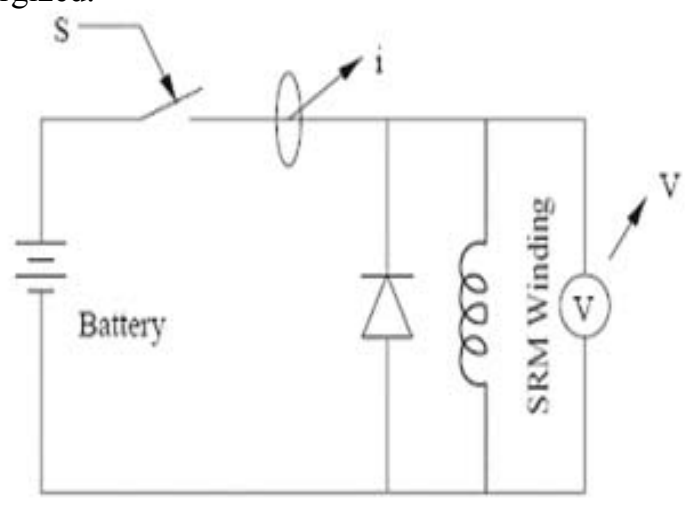

Figure 5 Measuring Circuit for SRM Flux Linkage Characteristics

A simplified measurement circuit for SRM flux linkage characteristics is shown in Figure 5. When a voltage pulse applied to any phase of the SRM while all other phases are open the voltage given by equation (5) [2].

$$
\begin{aligned}
& v=i r+\frac{d \lambda(i, \theta)}{d t} \\
& \lambda(i, \theta)=\int(v-i r) d t
\end{aligned}
$$

Where ' $\mathrm{v}$ ' voltage across phase winding

' $r$ ' resistance of the phase winding

$\lambda$ ' is flux linkage

From the equation (6) flux linkage can be calculated from any numerical integration technique the above equation is performed by using Simpson's 1/3 rd rule.

Simpson's $1 / 3$ rule :

Simpson's $1 / 3$ rule is one of the popular method of numerical integration and it is used for the measurement of definite integrals

$$
\begin{gathered}
\int \mathrm{Y}(\mathrm{x}) \mathrm{dx}=\mathrm{h} / 3[\mathrm{Y} 0+4 \mathrm{Y} 1+2 \mathrm{Y} 2+4 \mathrm{Y} 3+ \\
2 \mathrm{Yn}-2+4 \mathrm{Yn}-1+\mathrm{Yn}]
\end{gathered}
$$

In equation (7) $\mathrm{Y}(\mathrm{x})$ is the function and $\mathrm{Y} 0, \mathrm{Y} 1 \ldots \ldots \ldots . .$. the values of function at specified intervals and $h$ is the interval period.

\section{EXPERIMENTAL SETUP}

The proposed method has been tested using an experimental $0.5-\mathrm{kW} 42-\mathrm{V}$ four-phase 8/6 SRM drive, which is design for submersible pump and further specification of motor is mentioned in Table $\mathbf{- 2}$. The dc resistance of motor phase winding is measured using Voltmeter- Ammeter method and it is found $3.321 \mathrm{ohms}$.

TABle 2: Motor Specifications Of SRM SubMersible PumP

\begin{tabular}{|c|l|}
\hline VII. PARAMETER & Value \\
\hline Number of phase & 4 \\
\hline
\end{tabular}




\begin{tabular}{|l|l|}
\hline Number of Stator poles & 8 \\
\hline Number of rotor poles & 6 \\
\hline Stator Inner diameter & $50 \mathrm{~mm}$ \\
\hline Rotor outer diameter & $49 \mathrm{~mm}$ \\
\hline Stack length & $102 \mathrm{~mm}$ \\
\hline Stator arc & $10 \mathrm{~mm}$ \\
\hline Rotor arc & $08 \mathrm{~mm}$ \\
\hline Airgap length & $0.3 \mathrm{~mm}$ \\
\hline Shaft Diameter & $19 \mathrm{~mm}$ \\
\hline
\end{tabular}

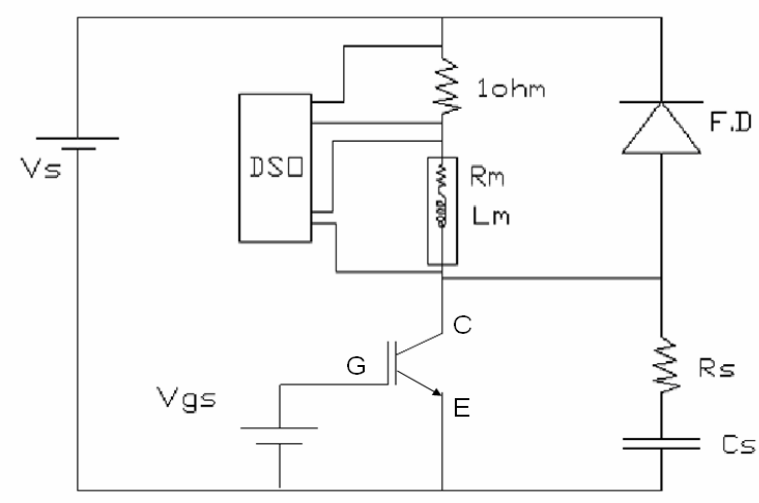

Figure 6 Experimental Setup

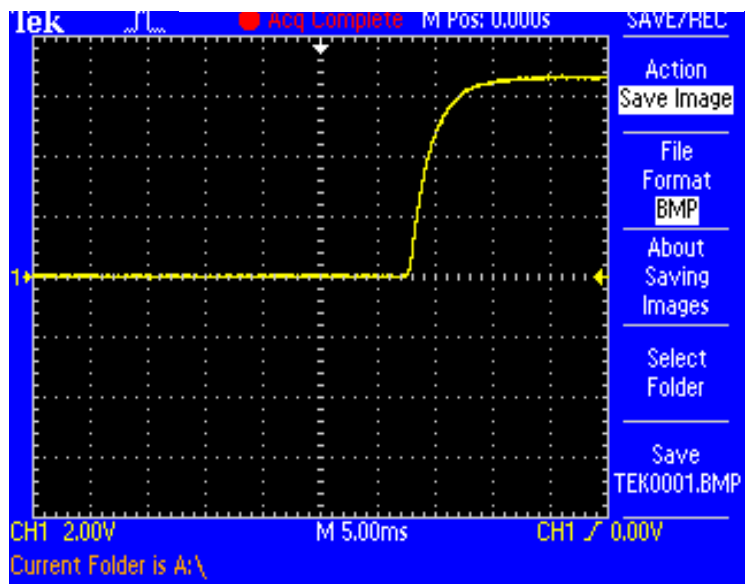

Figure 7 Current through the motor phase winding

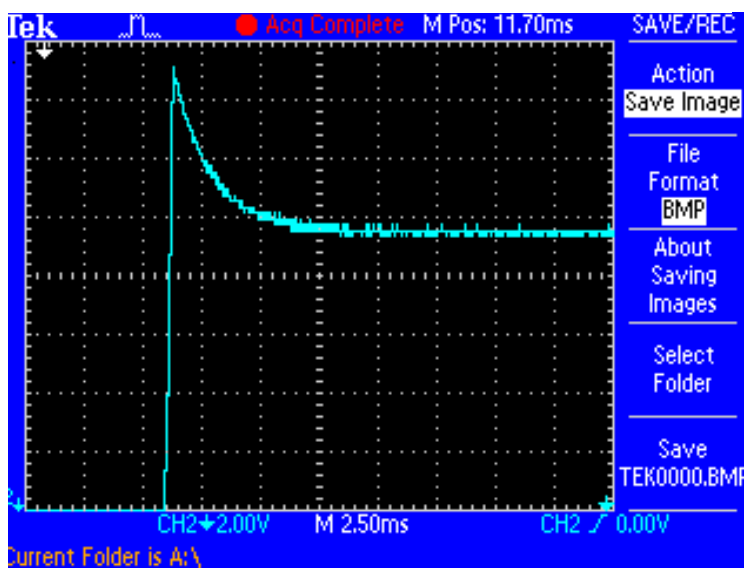

Figure 8 Voltage across the motor phase winding

The experimental setup is shown in Figure - 6. An IGBT is used as a switching device in each phase of SRM. Freewheeling diode is connected across the motor winding for dissipates the stored energy and an R-C snubber circuit is used for the protection of the switching device IGBT. A voltage pulse applied by turning on the switch and the voltage and current waveforms are recorded during short duration through digital storage oscilloscope. A digital storage oscilloscope (TDS 2100 TEKTRONIX) is used to acquire and store the current and voltage waveforms digitally.

A mechanist's dividing head (indexing head) is used to hold the rotor in position against high torque produced during the experiment current. Any one of the phase is connected to dc supply while all other phases open. The current and voltage waveforms across the phase winding are capture is DSO as shown in Figure - 7 and Figure - 8. Digitally stored voltage and current waveform is applied in equation $(6 \& 7)$ to calculate the flux linkage at different current levels of a $0.5 \mathrm{kw} 8 / 6 \mathrm{SRM}$ is obtained. The flux linkage at equally spaced rotor positions between unaligned to aligned positions are recorded as given in Table $\mathbf{- 3}$

\section{VIII.RESULTS AND DISCISSION}

The experimental results were obtained on the basis of captured voltage and current waveform at different rotor position, flux linkage is calculated using simpson's $1 / 3$ rule as per equation (7). The flux linkage at different rotor position for various current values is given in Table $-\mathbf{3}$. The flux linkage profile of the motor based on experiments is shown in Figure - 9.

TABLE -3 FLUX LINKAGE CHARACTERISTICS

\begin{tabular}{|c|c|c|c|c|c|}
\hline \multirow{2}{*}{$\begin{array}{l}\text { Curren } \\
\mathrm{t} \text { in } \\
\text { Amp }\end{array}$} & \multicolumn{5}{|c|}{$\begin{array}{l}\text { Flux Linkage in } \mathrm{mWb} \text { at } \\
\text { Different Rotor Position }\end{array}$} \\
\hline & $\begin{array}{l}0 \\
\operatorname{deg}\end{array}$ & $\begin{array}{l}8 \\
\text { deg }\end{array}$ & $\begin{array}{l}16 \\
\text { deg }\end{array}$ & $\begin{array}{l}25 \\
\text { deg }\end{array}$ & $\begin{array}{l}30 \\
\text { deg }\end{array}$ \\
\hline 0 & 0 & 0 & 0 & 0 & 0 \\
\hline 0.5 & 1.2 & 1.8 & 2.4 & 2.7 & 4.8 \\
\hline 0.948 & 2 & 3 & 3.9 & 4.8 & 6.8 \\
\hline 1.481 & 3.3 & 3.9 & 5 & 6.6 & 9.8 \\
\hline 2.104 & 4.5 & 5 & 7.2 & 9.3 & $\begin{array}{r}13 . \\
4\end{array}$ \\
\hline 2.667 & 5.7 & 6.6 & 8.7 & $\begin{array}{r}11 . \\
7\end{array}$ & $\begin{array}{r}16 . \\
1\end{array}$ \\
\hline 3.289 & 6.6 & 7.8 & 11 & $\begin{array}{r}14 . \\
4\end{array}$ & $\begin{array}{r}19 . \\
5\end{array}$ \\
\hline 3.763 & 7.5 & 8.5 & $\begin{array}{r}12 . \\
3\end{array}$ & $\begin{array}{r}16 . \\
8\end{array}$ & $\begin{array}{r}22 . \\
2 \\
\end{array}$ \\
\hline 4.44 & 8.7 & 10 & 15 & 20 & $\begin{array}{r}26 . \\
7\end{array}$ \\
\hline 5.03 & 9.6 & 11 & $\begin{array}{r}17 . \\
4\end{array}$ & 23 & 30 \\
\hline 5.68 & $\begin{array}{r}10 . \\
7\end{array}$ & $\begin{array}{r}12 . \\
6\end{array}$ & $\begin{array}{r}19 . \\
2\end{array}$ & 26 & $\begin{array}{r}35 . \\
1\end{array}$ \\
\hline 6.45 & $\begin{array}{r}11 . \\
7\end{array}$ & $\begin{array}{r}13 . \\
5\end{array}$ & $\begin{array}{r}22 . \\
8\end{array}$ & $\begin{array}{r}30 . \\
8\end{array}$ & $\begin{array}{r}39 . \\
8\end{array}$ \\
\hline 7.04 & 13 & $\begin{array}{r}15 . \\
2\end{array}$ & 25 & 34 & $\begin{array}{r}44 . \\
6\end{array}$ \\
\hline 7.51 & 14 & $\begin{array}{r}16 . \\
6\end{array}$ & $\begin{array}{r}26 . \\
9\end{array}$ & 37 & $\begin{array}{r}47 . \\
3\end{array}$ \\
\hline
\end{tabular}




\begin{tabular}{|r|r|r|r|r|r|}
\hline & & 17. & 28. & 39. & \\
8.01 & 15 & 9 & 5 & 7 & 50 \\
\hline & & 19. & & 41. & \\
8.51 & 16 & 3 & 30 & 8 & 52 \\
\hline & 16. & 20. & 31. & 43. & \\
9.01 & 5 & 5 & 5 & 5 & 54 \\
\hline & & & 33. & & 55. \\
9.51 & 17 & 21 & 1 & 45 & 8 \\
\hline & 18. & 22. & & & 57. \\
10 & 1 & 4 & 34 & 46 & 3 \\
\hline & 19. & 22. & 35. & 46. & \\
10.5 & 1 & 9 & 6 & 8 & 58 \\
\hline & 19. & & 36. & 47. & 58. \\
11 & 6 & 24 & 5 & 5 & 5 \\
\hline & 22. & 27. & 38. & 48. & 58. \\
12.68 & 2 & 2 & 2 & 5 & 8 \\
\hline
\end{tabular}

As the flux linkage of the motor is determined at different rotor position for particular phase, the inductance of the motor is calculated. The results are presented in Table $-\mathbf{4}$ and inductance profile is shown in Figure - 10 .

TABLE - 4 INDUCTANCE PROFILE OF SRM

\begin{tabular}{|c|c|c|c|c|c|c|}
\hline \multirow{2}{*}{$\begin{array}{c}\text { Roto } \\
\text { Positio } \\
n\end{array}$} & \multicolumn{6}{|c|}{ Inductance in mH } \\
\cline { 2 - 7 } & $1 \mathrm{~A}$ & $2 \mathrm{~A}$ & $5 \mathrm{~A}$ & $7 \mathrm{~A}$ & $9 \mathrm{~A}$ & $11 \mathrm{~A}$ \\
\hline 0 & 2.11 & 2.01 & 1.91 & 1.88 & 1.83 & 1.78 \\
\hline 8 & 3.16 & 2.84 & 2.58 & 2.38 & 2.28 & 2.18 \\
\hline 16 & 4.3 & 3.97 & 3.71 & 3.5 & 3.36 & 3.2 \\
\hline 25 & 5.64 & 5.25 & 5.07 & 4.81 & 4.67 & 4.32 \\
\hline 0 & 6.57 & 6.08 & 5.84 & 5.45 & 5.13 & 4.71 \\
\hline
\end{tabular}

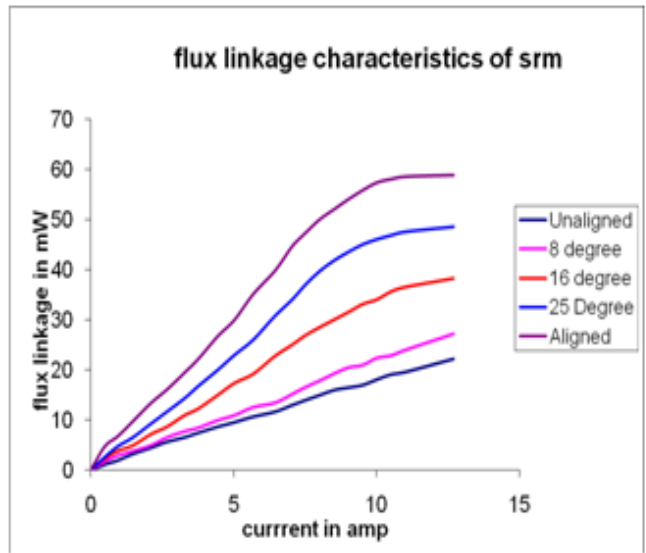

Figure - 9 Flux Linkage Characteristics of SRM

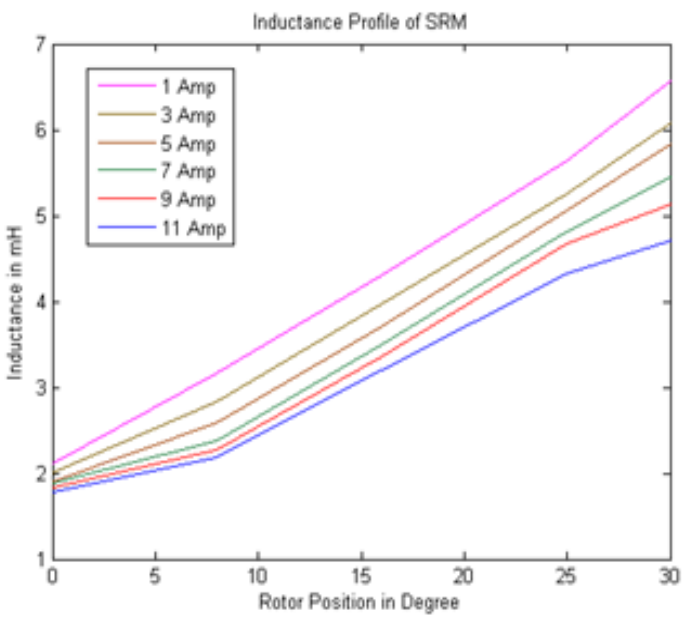

Figure 10 Inductance profile of SRM of Test Results

\section{REFERENCES}

[1] Ferrero A., Raciti A., "A Digital Method For Determination Of Magnetic Characteristic Of Variable Reluctance Motor" IEEE Transactions On Instrumentation \& Measurement. Vol.39. No.4, August 1990. Pp. 604-608.

[2] V. Ramnaryannan, L Venkatesha, Debi Prasad Panda," Flux Linkage Characteristic Of Switched Reluctance Motor" Power Electronics Drive And Energy System Conf. (PEDES'96), Delhi Dec. 1996. Pp.281-285.

[3] H. Cailleux, J-C. Mouchoux, B. Multon, E.Hoang, J-Y. Le Chenadec.," Comparison Of Measurement Methods to Determine the Electromagnetic Characteristics Of Switched Reluctance Motors". Electric drive design and applications (EPE Chapter drives), Lausanne, 19-20 oct. 1994 , pp. 639-644.

[4] Silverio Bolognani , Giuseppe S. Buja and Maria I. valla. "Switched Reluctance Motor Performance analysis Based On an Improved Modeling Of Its Magnetic characteristics.” Electric Machines And Power Systems, pp No. 425-38. 1991.

[5] Chris S. Edrington, , Babak Fahimi, and Mahesh Krishnamurthy "An Autocalibrating Inductance Model for Switched Reluctance Motor Drives" IEEE Transactions on Industrial Electronics, Vol. 54, No. 4, pp 2165-2172, August 2007.

[6] R. Krishnan, "Switched Reluctance Motor Drives: Modeling, Simulation, Analysis, Design and Applications" CRC Press.

[7] H.-P. Chi, R.-L. Lin and J.-F. Chen, "Simplified flux-linkage model for switched-reluctance motors” IEE Proc.-Electr. Power Appl., Vol. 152, No. 3, PP 577 - 583, May 2005.

[8] Tian Hua and Ching Gua Chen, "Implementation of a Sensorless Switched Reluctance Drive with Self Inductance Estimating Technique" IEEE Industrial Electronics Conference, PP 508 - 513, 2002.

[9] Yogesh Pahariya, Rakesh Saxena and Bhim Singh "Switched Reluctance Motor Drive: A New Concept in Variable Speed Drive" IEEMA Journal, Volume XXV, no.10, PP 72 - 76, October 2005. 